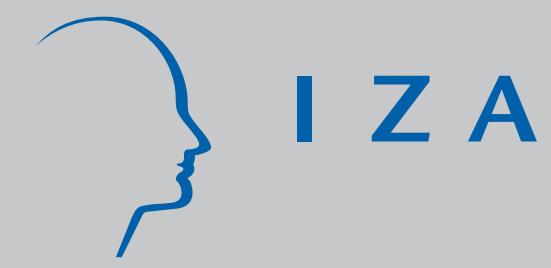

IZA DP No. 500

Estimating the Returns to Education Using the Newest Current Population Survey Education Questions

David A. J aeger

May 2002 


\title{
Estimating the Returns to Education Using the Newest Current Population Survey Education Questions
}

\author{
David A. Jaeger \\ College of William and Mary \\ and IZA Bonn
}
Discussion Paper No. 500
May 2002

\author{
IZA \\ P.O. Box 7240 \\ D-53072 Bonn \\ Germany \\ Tel.: +49-228-3894-0 \\ Fax: +49-228-3894-210 \\ Email: iza@iza.org
}

This Discussion Paper is issued within the framework of IZA's research area Evaluation of Labor Market Policies and Projects. Any opinions expressed here are those of the author(s) and not those of the institute. Research disseminated by IZA may include views on policy, but the institute itself takes no institutional policy positions.

The Institute for the Study of Labor (IZA) in Bonn is a local and virtual international research center and a place of communication between science, politics and business. IZA is an independent, nonprofit limited liability company (Gesellschaft mit beschränkter Haftung) supported by the Deutsche Post AG. The center is associated with the University of Bonn and offers a stimulating research environment through its research networks, research support, and visitors and doctoral programs. IZA engages in (i) original and internationally competitive research in all fields of labor economics, (ii) development of policy concepts, and (iii) dissemination of research results and concepts to the interested public. The current research program deals with (1) mobility and flexibility of labor, (2) internationalization of labor markets, (3) the welfare state and labor markets, (4) labor markets in transition countries, (5) the future of labor, (6) evaluation of labor market policies and projects and (7) general labor economics.

IZA Discussion Papers often represent preliminary work and are circulated to encourage discussion. Citation of such a paper should account for its provisional character. A revised version may be available on the IZA website (www.iza.org) or directly from the author. 
IZA Discussion Paper No. 500

May 2002

\section{ABSTRACT \\ Estimating the Returns to Education Using the Newest Current Population Survey Education Questions*}

This paper examines the 1997 additions to the Current Population Survey education question. These new questions allow researchers to come closer to the "highest grade completed" measure available before 1992. Using the new information, the average imputed "highest grade completed" is one-tenth grade greater and the estimated return to education .6 to 1 percentage points lower than when using only the post-1991 "highest degree received" question.

JEL Classification: J3, I2

Keywords: Current Population Survey, education

David A. Jaeger

Department of Economics

College of William and Mary

Williamsburg, VA 23187-8795

USA

Tel.: +1(757) 221-2375

Fax: +1(630) 214-4112

Email: djaeger@wm.edu

* The author thanks Alison Beach, Anne Polivka, and Bill Rodgers for comments. 


\section{Introduction}

In 1992 the Bureau of Labor Statistics (BLS) and the Bureau of the Census changed the educational attainment question in the Current Population Survey (CPS) from one that asked respondents to report the highest grade that they had completed to one that asked them to report the highest degree that they had received. The shift from a "time spent in school" measure to a focus on degrees received, which can take varying amounts of time, caused a break in the long time series on educational attainment available in the CPS. Jaeger (1997) proposes a variety of methods for reconciling responses to the two questions that focus on the distribution of measured educational attainment as well as the returns to education. To address the discontinuity induced by the 1992 change, the BLS began collecting data in 1997 from an expanded set of educational attainment questions that provide more information on the length of time spent in school. ${ }^{1}$

In this paper I document the additional CPS educational attainment questions, most of which are designed to provide more accurate measures of the amount of time spent in post-secondary and post-graduate study. Comparing the new information to the "linearization" of the "highest degree received" question proposed in Jaeger (1997), I find that using the new questions increases the average highest grade completed by about one-tenth of a grade, with the changes concentrated in the upper part of the educational distribution. I also find that the estimated return to education using "highest grade completed" imputed from the new information is about .6 to 1 percentage points smaller than the return estimated using only the linearized "highest degree received" question. Both the distribution of "highest grade completed" and the returns to education using the new information are closer to those using the "old" pre-1992 actual highest degree received measure. Researchers using the CPS to track changes over time in the distribution of education (as measured by "highest grade completed") or returns to education should be aware, however, that using the new information

\footnotetext{
${ }^{1}$ The new information is available on the monthly public-use files of the CPS beginning in January, 1998.
} 
induces a change in these measures in comparison to using only post-1991 "highest degree received" question.

\section{The Newest CPS Education Questions}

The newest CPS education questions are all contingent on responses to the post-1991 "highest degree received" question. Figure 1 shows the CPS education questions asked since 1997: the base "highest degree received" question and the responses to that question that trigger the eight additional questions. Individuals who respond that they have completed a high school diploma or equivalent are now also asked whether that diploma or equivalent is a traditional high school degree or a GED. For individuals who respond that they received a GED, an additional question probes for highest grade that they completed prior to earning the GED. The remaining questions all are designed to ascertain how many years of post-secondary or post-graduate study individuals completed.

Table 1 presents the distribution of responses to the base "highest degree received" question, as well as the contingent questions, for individuals age 25-64 in the March 1998 Current Population Survey. ${ }^{2}$ For comparison to Jaeger (1997), I present results for whites and non-whites for men and women as well as for the full sample. Note that the shares sum to one within each question and subgroup. Ten percent of high school credentials are were earned via the GED, and more than 80 percent of those with a GED finished less than 12 years of schooling. There is a fair amount of variation in the time spent in school among those with less than a four-year college degree as well, with more than half of individuals who report having "some college" having completed more than 1

\footnotetext{
${ }^{2}$ I use the March data to facilitate comparisons to results from the March 1991-92 data presented in Jaeger (1997). In addition, March 1998 is the earliest publicly-available demographic supplement with the new education questions. Moreover, because the new questions were asked beginning in January 1997, there is a sufficiently long "shakedown" period (Frazis and Stewart 1999) for the interviewers to gain experience asking them prior to the data used in this paper. Individuals who had an allocated value for "highest degree received" were dropped from the sample.
} 
year of college credit. Moreover, a substantial share of Bachelor's degree holders (roughly 30 percent) report completing some post-graduate studies.

\section{Imputing Highest Grade Completed}

I present a method of imputing highest grade completed from the new CPS educational attainment questions in Table 2. This extends the imputations proposed by Jaeger (1997) that best matched "highest degree received" question to the pre-1992 question on highest grade completed in terms of the distribution of, and returns to, education. For GED recipients, the imputed highest grade completed is the grade that they finished before receiving their GED, while traditional high school degree recipients are assumed to have completed 12th grade. The imputations for "some college" or either type of an Associate's degree imputes 12th grade through 16th grade completion for individuals who complete less than one through four or more years of college credit, respectively.

Following Jaeger (1997), I top-code the highest grade completed at 18 because the highest grade completed in the pre-1992 question was top-coded at 18. This is the top code value for the pre-1992 "highest degree received" question. Zero through six post-B.A. courses are assumed to constitute one year and are assigned a highest grade completed of 17, while more than six post-B.A. courses are assigned a highest grade completed of 18. Two and three year M.A. programs are also assigned a highest grade completed of 18 , while one year programs are assigned a value of 17 . Like Jaeger (1997), I assign a highest grade completed of 18 to professional and Doctoral degrees.

The distribution of imputed highest grade completed using only the "highest degree received" question (denoted "New") and this question plus the additional questions (denoted "New+") are shown in Table 3. The average highest grade completed increased by about .11 grades when using the new questions for the full sample and for all subgroups; these differences are statistically significantly different from zero. Among the approximately 25 percent of the sample whose imputed highest grade completed is different between the two measures, the average increase was about .46 grades. These differences are driven by changes in imputed highest grade for individuals who 
completed more than 12 th grade. There was a substantial decrease in the share of individuals with an imputed highest grade completed of 13, who generally moved up the distribution to 14 or 15 . Similarly, the question on post-graduate study decreased the share of individuals with an imputed highest grade completed of 16 and moved them up to 17 or 18 . Both of these shifts were more pronounced for women than for men, in part because women less likely to have a professional or Doctoral degree, for which there are no new questions.

\section{Estimating the Return to Education}

These changes in the imputed highest grade completed, more frequent at levels of education above high school and below professional and Doctoral degrees, imply that the estimated return to education is likely to be lower using the "New+" measure. To gauge the impact of using the new information, I estimated regressions of log hourly wage on imputed highest grade completed, which are reported in Table $3 .^{3}$ Because actual work experience is not recorded in the CPS, I control for experience using the conventional "potential experience" measure (potential experience = age imputed highest grade completed - 6) in one set of regressions. This measure is a function of imputed highest grade completed, so I also present results using age as a proxy for actual experience. Where appropriate, the regressions include indicators for "non-white" and for "female." For comparison, results from Jaeger (1997) using a matched sample of the March 1991-92 data to estimate the sample models are also shown. The columns marked "Old" use the pre-1992 question on "highest grade completed," the columns marked "New" use highest grade completed imputed from the "highest degree received" question by itself, and the columns marked "New + " use highest grade completed imputed from this question plus the new set of questions. Note that measure used in the "New" columns is the same across the 1991-92 and 1998 data, so that changes in the estimated

3 Hourly earnings from the March supplement are defined as annual wage and salary income $\div$ (weeks worked $\times$ usual hours worked per week). The regression samples exclude individuals with hourly earnings of less than $\$ 1$ and greater than $\$ 200$. 
using this measure are solely driven by changes over time. Heteroskedasticity-consistent standard errors are presented in all columns and the standard error for the difference between the estimates using "New" and "New+" measures in 1998 are calculated using 1,000 bootstrap samples.

In general, the estimated returns using the "New+" measure are about .6 to 1 percentage points less than those estimated using the "New" measure, depending on the subgroup and the experience measure used. For the full sample, the estimated return falls approximately .86 percentage points, from .105 to .097 using potential experience, and from .097 to .088 using age. The difference is bigger for the youngest subgroups (age 25-35 and age 36-46), who are more likely to have more than a high school education. Consistent with this, the difference between the estimates using "New+" and "New" measures is also bigger for women and for whites. For all subgroups, this difference is statistically significantly different from zero.

Using the return to education as a metric, the additions to the educational attainment question in the CPS would appear permit researchers to come closer to the pre-1992 highest grade completed question. The estimated returns to education using the "New+" measure are generally quite close those estimated using actual highest grade completed from the pre-1992 question. The estimate using the "New+" measure (in 1998) exceeds the estimate using the "Old" measure (in 1992) by less than .4 percentage points in the full sample. Note, however, that the estimated return using the "New" variable grew by about 1 percentage point for most groups between 1992 and 1998. If we use the growth in the return using this variable to adjust downward the estimated return using the "New+" mesaure, the estimated return in the full sample would be about .4 percentage points less than the estimate using the "Old" measure. Applying this adjustment to the other subgroups yields estimated returns using the "New+" measure that are between .1 and .7 percentages points less than the estimated return using the "Old" measure. 


\section{Conclusion}

Using the additional educational attainment questions in the Current Population Survey available after 1997, I found that the estimated return to education from a linear "highest grade completed" measure constructed from those questions was approximately .6 to 1 percentage points less than the return estimated using only the information from the "highest degree received" question introduced in 1992. Using the new questions increased the overall average imputed "highest grade completed" by about .1 grades, and by about half of a grade for the 25 percent of individuals whose imputed value was changed by incorporating the new information. This shift came mostly from individuals with "some college" moving up the distribution as well as from a substantial share of Bachelor's degree recipients who have some post-graduate education. The additional questions come closer to the pre-1992 measure of "highest grade completed," and researchers who use this measure in the CPS before 1992 and after 1997 are likely to want to use the new information to make the data as comparable as possible. Researchers examining the period from 1992 to 1997 when only the "highest degree received" measure is available and comparing to later years, when the new questions are asked, should be aware that using the new information will affect both the measured distribution of, and the estimated return to, education.

\section{REFERENCES}

Frazis, Harley and Jay Stewart. 1999. "Tracking the Returns to Education in the 1990s: Bridging the Gap Between the New and Old Current Population Survey Education Items," Journal of Human Resources 34(3): 629-641.

Jaeger, David A. 1997. "Reconciling the New Census Bureau Education Questions: Recommendations for Researchers," Journal of Business and Economic Statistics 15(4): 300309. 


\section{Figure 1}

\section{Structure of Revised Current Population Survey Education Questions}

(questions are denoted by $\Rightarrow$, response categories are denoted by $\bullet$, contingent questions are denoted by indentation, ... indicates fill-in for individual's name)

$\Rightarrow$ "What is the highest level of school ... completed or the highest degree ... received?"

- 31 Less than 1 st grade

- 32 1st, 2nd, 34d, or 4th grade

- 334 th or 6 th grade

- 347 th or 8 th grade

- 35 9th grade

- 36 10th grade

- 37 11th grade

- 38 12th grade, no diploma

- 39 High School Grade - Diploma or Equivalent (GED)

$\Rightarrow$ "People can get their High School diploma in a variety of ways, such as graduation from High School or by getting a GED or other equivalent. How did ... get ...'s High School Diploma?"

- 1 Graduation from High School

- 2 GED or other equivalent

$\Rightarrow$ "What was the highest grade of regular school ... completed before receiving ...'s GED?"

- 1 Less than 1 st grade

- 21 st, 2nd, 34d, or 4th grade

- 34 th or 6 th grade

- 47 th or 8 th grade

- 5 9th grade

- 6 10th grade

- 7 11th grade

- 8 12th grade, no diploma 
- 40 Some College but no degree

$\Rightarrow$ Years of college credit completed

- 1 Less than 1 year (includes 0 years completed)?

- 2 The first, or Freshman year?

- 3 The second, or Sophomore year?

- 4 The third, or Junior year?

- 5 Four or more years?

- 41 Associate Degree - Occupation/Vocational

$\Rightarrow$ Years of college credit completed (same choices as above)

- 42 Associate Degree - Academic Program

$\Rightarrow$ Years of college credit completed (same choices as above)

- 43 Bachelor's Degree (ex.: B.A., A.B., B.S.)

$\Rightarrow$ "Since completing ... Bachelor's degree, has ... taken any graduate or professional school courses for credit?"

- 1 Yes

$\Rightarrow$ "Did ... complete 6 or more graduate or professional school courses?"

- 1 Yes

- 2 No

- 2 No

- 44 Master's Degree (ex.: M.A., M.S., M.Eng., M.Ed., M.S.W.)

$\Rightarrow$ "Was ... Master's Degree program a 1 year, 2 year, or 3 year program?"

- 11 year program

- 2 year program

- 33 year program

- 45 Professional School Degree (ex.: M.D., D.D.S., D.V.M.)

- 46 Doctorate Degree (ex.: Ph.D., Ed.D) 
Table 1

Distribution of Educational Attainment

\begin{tabular}{|c|c|c|c|c|c|}
\hline \multirow[b]{2}{*}{ Education Category/Subcategory } & \multirow[b]{2}{*}{ All } & \multicolumn{2}{|c|}{ Men } & \multicolumn{2}{|c|}{ Women } \\
\hline & & White & $\begin{array}{l}\text { Non- } \\
\text { White }\end{array}$ & White & $\begin{array}{l}\text { Non- } \\
\text { White }\end{array}$ \\
\hline Less than 1st grade & .003 & .003 & .006 & .003 & .006 \\
\hline $1 \mathrm{st}, 2 \mathrm{nd}, 3 \mathrm{rd}$, or 4 th grade & .008 & .009 & .008 & .007 & .006 \\
\hline 5 th or 6 th grade & .017 & .018 & .015 & .016 & .014 \\
\hline 7 th or 8 th grade & .021 & .022 & .019 & .019 & .021 \\
\hline 9 th grade & .018 & .018 & .021 & .018 & .022 \\
\hline 10th grade & .026 & .026 & .033 & .023 & .034 \\
\hline 11th grade & .029 & .026 & .053 & .023 & .047 \\
\hline 12th grade no diploma & .012 & .011 & .019 & .009 & .021 \\
\hline High school grade or GED & .335 & .321 & .341 & .347 & .333 \\
\hline Graduation from high school & .894 & .880 & .904 & .901 & 910 \\
\hline GED or other equivalent & .106 & .120 & .096 & .099 & .090 \\
\hline Less than 1st & .023 & .024 & .040 & .015 & .044 \\
\hline 1 st, 2 nd, 3rd, or 4th grade & .002 & .001 & .005 & .000 & .006 \\
\hline 5 th or 6 th grade & .008 & .002 & .003 & .014 & .014 \\
\hline 7 th or 8 th grade & .057 & .055 & .054 & .063 & .049 \\
\hline 9th grade & .138 & .146 & .116 & .138 & .104 \\
\hline 10th grade & .249 & .238 & .235 & .272 & .210 \\
\hline 11th grade & .372 & .363 & .372 & .372 & 419 \\
\hline 12th grade no diploma & .152 & .171 & 176 & .126 & .155 \\
\hline Some college, no degree & .181 & .175 & .183 & .183 & .194 \\
\hline Less than 1 year of college credit completed & .156 & .155 & .151 & .164 & .130 \\
\hline 1 year of college credit completed & .332 & .310 & .303 & .354 & .345 \\
\hline 2 years of college credit completed & .357 & .365 & .355 & .349 & .362 \\
\hline 3 years of college credit completed & .123 & .134 & .148 & .103 & .137 \\
\hline 4 or more years of college credit completed & .033 & .036 & .042 & .029 & .026 \\
\hline Occupational Ássociate's degree & .043 & .043 & .033 & .046 & .042 \\
\hline Less than 1 year of college credit completed & .086 & .096 & .092 & .074 & .099 \\
\hline 1 year of college credit completed & .138 & .106 & .151 & .158 & .178 \\
\hline 2 years of college credit completed & .589 & .612 & .569 & .576 & .560 \\
\hline 3 years of college credit completed & .131 & .127 & .134 & .140 & .108 \\
\hline 4 or more years of college credit completed & .055 & .059 & .054 & .053 & .055 \\
\hline Academic Associate's degree & .040 & .036 & .028 & .046 & .036 \\
\hline Less than 1 year of college credit completed & .023 & .023 & .001 & .024 & .032 \\
\hline 1 year of college credit completed & .048 & .044 & .071 & .046 & .062 \\
\hline 2 years of college credit completed & .658 & .654 & .699 & .658 & .651 \\
\hline 3 years of college credit completed & .188 & .187 & .149 & .196 & .173 \\
\hline 4 or more years of college credit completed & .083 & .092 & .080 & .076 & .082 \\
\hline Bachelor's degree & .183 & 190 & .160 & .185 & .159 \\
\hline 0 graduate courses past B.A. & .687 & .718 & .743 & .644 & .709 \\
\hline $0<$ graduate courses $<6$ past B.A. & .133 & .118 & .116 & .152 & .130 \\
\hline$>=6$ graduate courses past B.A. & .179 & .164 & .141 & .204 & .161 \\
\hline Master's degree (e.g. MA, MSW) & .058 & .061 & .054 & .058 & .050 \\
\hline 1 year program & .122 & .114 & .129 & .133 & .107 \\
\hline 2 year program & .608 & .610 & .669 & .600 & .587 \\
\hline 3 year program & .269 & .275 & .202 & .268 & .306 \\
\hline Professional school degree (e.g. MD, DDS, JD) & .016 & .023 & .016 & .010 & .009 \\
\hline Doctorate degree $(\mathrm{PhD}, \mathrm{EdD})$ & .011 & .017 & .012 & .007 & .005 \\
\hline $\mathrm{Sh}$ & 1.000 & .413 & .076 & .421 & .091 \\
\hline$N$ & 61,503 & 25,460 & 3,969 & 26,935 & 5,139 \\
\hline
\end{tabular}

SOURCE: Weighted 1998 March Current Population Survey.

NOTE: Individuals 25-64 years old. 
Table 2

Imputations of Highest Grade Completed

for Newest CPS Educational Attainment Questions

Imputed

Highest

Grade

Education Question

Completed

Highest Grade/Degree Completed is

$<1$ st grade

$1 \mathrm{st}, 2 \mathrm{nd}, 3 \mathrm{rd}$, or 4 th grade

5 th or 6 th grade

7 th or 8 th grade

9th grade

10th grade

11 th grade

12th grade, no diploma

Highest Grade/Degree Completed is GED/HS Diploma AND

Received GED or Equivalent AND Highest Grade Completed before GED was

$<1$ st grade

1st, 2nd, 3rd, or 4th grade $\quad 2.5$

5 th or 6th grade $\quad 5.5$

7th or 8 th grade $\quad 7.5$

9th grade 9

$\begin{array}{ll}10 \text { th grade } & 10\end{array}$

11th grade 11

12th grade, no diploma $\quad 12$

Received HS Diploma 12

Some College OR Occupational or Academic Associate's Degree AND

Years of College Credit Completed is

$<1$ year (includes 0 )

First, or Freshman year 13

Second, or Sophomore year 14

Third, or Junior year $\quad 15$

$\begin{array}{ll}\text { Four or more years } & 16\end{array}$

Completed a Bachelor's Degree AND Graduate or Professional courses for credit is

None $\quad 16$

Greater than 0 and less than $6 \quad 17$

$\begin{array}{ll}\text { Greater than or equal to } 6 & 18\end{array}$

Completed an Master's Degree AND Program was a

1 year program 17

2 year program $\quad 18$

3 year program (or longer) $\quad 18$

Completed a Professional Degree 18

Completed a Doctoral Degree 18

NOTE: Imputed "Highest Grade Completed" is capped at 18 to be consistent with pre-1992 CPS education question. 
Table 3

Distribution of Imputed Highest Grade Completed

(standard errors of differences shown in parentheses)

\begin{tabular}{|c|c|c|c|c|c|c|c|c|c|c|}
\hline \multirow{3}{*}{$\begin{array}{l}\text { Imputed } \\
\text { Highest } \\
\text { Completed } \\
\end{array}$} & \multicolumn{2}{|c|}{ All } & \multicolumn{4}{|c|}{ Men } & \multicolumn{4}{|c|}{ Women } \\
\hline & \multirow[b]{2}{*}{ "New" } & \multirow[b]{2}{*}{ "New+" } & \multicolumn{2}{|c|}{ White } & \multicolumn{2}{|c|}{ Non-White } & \multicolumn{2}{|c|}{ White } & \multicolumn{2}{|c|}{ Non-White } \\
\hline & & & "New" & "New+" & "New" & "New+" & "New" & "New+" & "New" & "New+" \\
\hline 0 & .003 & .004 & .003 & .004 & .006 & .008 & .003 & .003 & .006 & .007 \\
\hline 2.5 & .008 & .008 & .009 & .009 & .008 & .008 & .007 & .007 & .006 & .006 \\
\hline 5.5 & .017 & .017 & .018 & .018 & .015 & .015 & .016 & .017 & .014 & .015 \\
\hline 7.5 & .021 & .023 & .022 & .024 & .019 & .021 & .019 & .022 & .021 & .022 \\
\hline 9 & .018 & .023 & .018 & .024 & .021 & .024 & .018 & .022 & .022 & .025 \\
\hline 10 & .026 & .035 & .026 & .035 & .033 & .040 & .023 & .032 & .034 & .040 \\
\hline 11 & .029 & .042 & .026 & .040 & .053 & .065 & .023 & .036 & .047 & .060 \\
\hline 12 & .347 & .349 & .333 & .333 & .360 & .364 & .356 & .361 & .355 & .360 \\
\hline 13 & .181 & .068 & .175 & .061 & .183 & .062 & .183 & .074 & .194 & .077 \\
\hline 14 & .083 & .116 & .079 & .114 & .061 & .103 & .092 & .120 & .078 & .117 \\
\hline 15 & .000 & .035 & .000 & .036 & .000 & .036 & .000 & .034 & .000 & .038 \\
\hline 16 & .183 & .137 & .190 & .148 & .160 & .130 & .185 & .130 & .159 & .123 \\
\hline 17 & .000 & .040 & .000 & .038 & .000 & .030 & .000 & .045 & .000 & .031 \\
\hline 18 & .085 & .103 & .101 & .116 & .082 & .094 & .076 & .096 & .064 & .079 \\
\hline Mean & 13.136 & 13.249 & 13.223 & 13.332 & 12.920 & 13.025 & 13.146 & 13.264 & 12.875 & 12.989 \\
\hline Mean ("New+" - "New") Difference & \multicolumn{2}{|c|}{$\begin{array}{c}.113 \\
(.004)\end{array}$} & \multicolumn{2}{|c|}{$\begin{array}{c}.109 \\
(.006)\end{array}$} & \multicolumn{2}{|c|}{$\begin{array}{c}.106 \\
(.015)\end{array}$} & \multicolumn{2}{|c|}{$\begin{array}{c}.118 \\
(.006)\end{array}$} & \multicolumn{2}{|c|}{$\begin{array}{c}.115 \\
(.013)\end{array}$} \\
\hline Mean Non-Zero Difference & \multicolumn{2}{|c|}{$\begin{array}{c}.459 \\
(.014)\end{array}$} & \multicolumn{2}{|c|}{$\begin{array}{c}.450 \\
(.024)\end{array}$} & \multicolumn{2}{|c|}{$\begin{array}{c}.470 \\
(.066)\end{array}$} & \multicolumn{2}{|c|}{$\begin{array}{c}.460 \\
(.021)\end{array}$} & \multicolumn{2}{|c|}{$\begin{array}{c}.487 \\
(.054)\end{array}$} \\
\hline Share with Non-Zero Difference & \multicolumn{2}{|c|}{.247} & \multicolumn{2}{|c|}{.242} & \multicolumn{2}{|c|}{.225} & \multicolumn{2}{|c|}{.257} & \multicolumn{2}{|c|}{.235} \\
\hline$N$ & \multicolumn{2}{|c|}{61,503} & \multicolumn{2}{|c|}{25,460} & \multicolumn{2}{|c|}{3,969} & \multicolumn{2}{|c|}{26,935} & \multicolumn{2}{|c|}{5,139} \\
\hline
\end{tabular}

SOURCE: Calculations from weighted March 1998 Current Population Survey.

NOTE: Individuals 25-64 years old. "New" denotes responses imputations using only the post-1991 "Highest Degree" question while "New+" indicates imputations using "Highest Degree" question plus additional questions asked after 1996. Standard errors calculated using 1,000 boostrap samples. 
Table 4

Estimated Return to Education

(heteroskedasticity-consistent standard errors in parentheses)

\begin{tabular}{|c|c|c|c|c|c|c|c|c|c|c|}
\hline \multirow[b]{3}{*}{ Subgroup } & \multicolumn{5}{|c|}{ Potential Experience } & \multicolumn{5}{|c|}{ Age } \\
\hline & \multicolumn{2}{|c|}{$1991-92$} & \multicolumn{3}{|c|}{1998} & \multicolumn{2}{|c|}{$1991-92$} & \multicolumn{3}{|c|}{1998} \\
\hline & Old & New & New & New + & Diff. & Old & New & New & New + & Diff. \\
\hline \multirow[t]{2}{*}{ Full Sample } & .093 & .097 & .105 & .097 & -.0085 & .085 & .089 & .097 & .088 & -.0087 \\
\hline & $(.002)$ & $(.002)$ & $(.001)$ & $(.001)$ & $(.0004)$ & $(.002)$ & $(.002)$ & $(.001)$ & $(.001)$ & $(.0004)$ \\
\hline$N$ & \multicolumn{2}{|c|}{19,230} & \multicolumn{3}{|c|}{45,342} & \multicolumn{2}{|c|}{19,230} & \multicolumn{3}{|c|}{45,342} \\
\hline \multicolumn{11}{|l|}{ Sex } \\
\hline \multirow[t]{2}{*}{ Men } & .086 & .090 & .101 & .094 & -.0076 & .076 & .080 & .090 & .082 & -.0079 \\
\hline & $(.002)$ & $(.002)$ & $(.002)$ & $(.002)$ & $(.0004)$ & $(.002)$ & $(.002)$ & $(.002)$ & $(.002)$ & $(.0004)$ \\
\hline$N$ & \multicolumn{2}{|c|}{9,959} & \multicolumn{3}{|c|}{23,109} & \multicolumn{2}{|c|}{9,959} & \multicolumn{3}{|c|}{23,109} \\
\hline \multirow[t]{2}{*}{ Women } & .102 & .105 & .110 & .100 & -.0096 & .097 & .100 & .104 & .094 & -.0097 \\
\hline & $(.003)$ & $(.003)$ & $(.002)$ & $(.002)$ & $(.0004)$ & $(.002)$ & $(.002)$ & $(.002)$ & $(.002)$ & $(.0004)$ \\
\hline$N$ & \multicolumn{2}{|c|}{9,271} & \multicolumn{3}{|c|}{22,233} & \multicolumn{2}{|c|}{9,271} & \multicolumn{3}{|c|}{22,233} \\
\hline \multicolumn{11}{|l|}{ Race } \\
\hline \multirow[t]{2}{*}{ Whites } & .092 & .095 & .106 & .097 & -.0086 & .084 & .088 & .097 & .088 & -.0088 \\
\hline & $(.002)$ & $(.002)$ & $(.001)$ & $(.001)$ & $(.0004)$ & $(.002)$ & $(.002)$ & $(.001)$ & $(.001)$ & $(.0004)$ \\
\hline$N$ & \multicolumn{2}{|c|}{16,946} & \multicolumn{3}{|c|}{38,838} & \multicolumn{2}{|c|}{16,946} & \multicolumn{2}{|c|}{38,838} & \\
\hline Non-Whites & .101 & .108 & .103 & .096 & -.0077 & .092 & .099 & .095 & .087 & -.0078 \\
\hline & $(.005)$ & $(.005)$ & $(.003)$ & $(.003)$ & $(.0004)$ & $(.005)$ & $(.005)$ & $(.003)$ & $(.003)$ & $(.0004)$ \\
\hline$N$ & 2,2 & 84 & & 6,504 & & & 84 & & 6,504 & \\
\hline Age & & & & & & & & & & \\
\hline $25-35$ & .109 & .112 & .122 & .113 & -.0092 & .085 & .088 & .095 & .085 & -.0099 \\
\hline & $(.004)$ & & $(.002)$ & $(.002)$ & $(.0004)$ & & $(.003)$ & $(.002)$ & $(.002)$ & $(.0004)$ \\
\hline$N$ & 5,4 & 01 & & 14,737 & & & 01 & & 14,737 & \\
\hline $36-46$ & .095 & .099 & .112 & .102 & -.0097 & .086 & .091 & .103 & .094 & -.0093 \\
\hline & $(.004)$ & $(.004)$ & $(.002)$ & $(.002)$ & $(.0004)$ & $(.003)$ & $(.003)$ & $(.002)$ & $(.002)$ & $(.0004)$ \\
\hline$N$ & 6,6 & 51 & & 16,069 & & & 51 & & 16,069 & \\
\hline $47-64$ & .081 & .085 & .089 & .082 & -.0066 & .084 & .087 & .092 & .085 & -.0069 \\
\hline & $(.003)$ & $(.003)$ & $(.002)$ & $(.002)$ & $(.0004)$ & $(.002)$ & $(.003)$ & $(.002)$ & $(.002)$ & $(.0004)$ \\
\hline$N$ & 7,1 & 78 & & 14,536 & & & 78 & & 14,536 & \\
\hline
\end{tabular}

SOURCES: 1991-92: Jaeger (1997), Table 4; 1998: Calculations from the March Current Population Survey

NOTE: Indviduals 25-64 years old. "Old" indicates pre-1992 "Highest Grade Completed" question, "New" indicates imputations using post-1991 "Highest Degree Received" question, and "New+" indicates imputations uisng "Highest Degree Received" question plus additional questions asked after 1996. Models estimated by OLS. Dependent vairable is $\log ($ hourly wage). Potential experience columns include experience and potential experience ${ }^{2} / 100$ as covariates. Age columns include (age-25) and (age-25) ${ }^{2}$ as covariates. Where appropriate, models also include dummy variables for female and nonwhite. Standard errors for differences estimated by the bootstrap with 1,000 samples. 


\section{IZA Discussion Papers}

No. Author(s)

484

J. H. Bishop

L. Woessmann

485

L. Woessmann

M. R. West

\section{A. L. Booth}

M. L. Bryan

487

488

R. L. Lumsdaine

E. S. Prasad

A. Ciccone

G. Peri

489

490

W. F. Richter

491

492

493

494

495

$$
\begin{aligned}
& \text { J. T. Addison } \\
& \text { L. Bellmann } \\
& \text { C. Schnabel } \\
& \text { J. Wagner }
\end{aligned}
$$

M. A. Shields
Title

Area

Date

Institutional Effects in a Simple Model of

5

04/02

Educational Production

Class-Size Effects in School Systems Around

5

04/02

the World: Evidence from Between-Grade

Variation in TIMSS

Who pays for General Training? New Evidence for British Men and Women

Identifying the Common Component of

2

04/02

International Economic Fluctuations:

A New Approach

Identifying Human Capital Externalities:

Theory with an Application to US Cities

Employment Patterns of Husbands and Wives

and Family Income Distribution in Italy (1977-

1998)

Social Security and Taxation of Labour Subject

2

to Subsidiarity and Freedom of Movement

On the Production of Victory: Empirical Deter-

minants of Battlefield Success in Modern War

Benefit Entitlement and Unemployment

Duration: The Role of Policy Endogeneity

6

05/02

Work-Related Stress, Quitting Intentions and

5

05/02

Absenteeism

The Role of the Regional Milieu for the Decision

05/02 to Start a New Firm: Empirical Evidence for Germany

German Works Councils Old and New:

Incidence, Coverage and Determinants

Polish Transition

European Integration and Employment:

A New Role for Active Fiscal Policies?

Individual Rationality and Learning: Welfare

6

05/02

J. P. Haisken-DeNew

Reunification

Tax Policy, Location Choices, and Market

6

$05 / 02$

H. van Kranenburg

Structure

Estimating the Returns to Education Using the Newest Current Population Survey Education Questions 